\title{
Expression of ER $\beta$, ER $\alpha$ and Her-2 and distribution of molecular subtypes in Uygur and Han patients with breast cancer
}

\author{
LIYING GUO $^{1}$, XUEQIN HOU ${ }^{1}$, YILAMU DILIMINA ${ }^{1}$ and BOWEI WANG ${ }^{2}$ \\ Departments of ${ }^{1}$ Breast Cancer, Digestive and Vascular Center, and ${ }^{2}$ Pathology, \\ The First Affiliated Hospital of Xinjiang Medical University, Urumchi, Xingjiang 830054, P.R. China
}

Received November 4, 2013; Accepted February 17, 2014

DOI: $10.3892 /$ etm.2014.1596

\begin{abstract}
The aim of the present study was to investigate the expression levels of estrogen receptor (ER) $\alpha$ and $\beta$ and human epidermal growth factor receptor-2 (Her-2), as well as the distribution of breast cancer molecular subtypes in Uygur and Han breast cancer patients. Cancer tissues were collected and analyzed from 709 breast cancer patients enrolled between January 2000 and December 2010. The expression levels of $\mathrm{ER} \alpha, \mathrm{ER} \beta$ and Her-2 were determined by immunohistochemistry. The differences in expression and molecular subtype distribution between Uygur and Han patients with breast cancer were analyzed using a Pearson's $\chi^{2}$ test. Statistically significant differences were observed in the expression levels of ER $\beta, E R \alpha$ and Her-2 between the Uygur and Han patients with breast cancer $(\mathrm{P}<0.05)$. The expression levels of $\operatorname{ER} \beta(++)$, $\operatorname{ER} \beta(+++)$ and Her-2 (+++) in Uygur patients were significantly higher, while the expression levels of ER $\alpha(+++)$ in Uygur patients were significantly lower when compared with Han patients. The percentage of luminal A type breast cancer in Uygur patients was significantly lower when compared with the Han patients, whereas the percentages of basal-like and Her-2 overexpression types were significantly higher than those in Han patients $(\mathrm{P}<0.05)$. Therefore, expression levels of $E R \beta$, $\mathrm{ER} \alpha$ and Her-2, and molecular subtypes of breast cancer were significantly different between the Uygur and Han populations.
\end{abstract}

\section{Introduction}

Breast cancer is a tumor with heterogeneity, which differs among ethnic groups and individuals (1). Ethnicity has been reported to be an independent factor affecting the prognosis of

Correspondence to: Dr Liying Guo, Department of Breast Cancer, Digestive and Vascular Center, The First Affiliated Hospital of Xinjiang Medical University, 137 South Liyushan Road, Urumchi, Xingjiang 830054, P.R. China

E-mail: gejsy318@126.com

Key words: breast cancer, ethnicity, estrogen receptor $\alpha$, estrogen receptor $\beta$, human epidermal growth factor receptor-2, molecular subtypes breast cancer (2). Estrogen receptor (ER) $\beta$, the newly identified ER subtype, has potentially important clinical value for the research of biological characteristics and prognosis evaluation of breast cancer. ER $\alpha$ and human epidermal growth factor receptor-2 (Her-2) are commonly used immunohistochemistry indicators in clinical practice. These receptors are important for the guidance of postoperative chemotherapy and endocrine therapy of breast cancer, as well as for the evaluation of breast cancer prognosis. Breast cancer may be divided into various molecular subtypes based on the expression levels of ER $\beta$, progesterone receptor and Her-2. Different molecular subtypes among various ethnicities have their own characteristics (3). In the present study, the expression levels of ER $\beta, E R \alpha$ and Her-2, as well as the distributions of various molecular subtypes, were compared between Uygur and Han patients with breast cancer in Xinjiang, China.

\section{Materials and methods}

Patient data. A total of 730 specimens from patients with pathologically confirmed invasive breast cancers were used in the study. Twenty-one cases were censored, since certain patients succumbed to other causes or were lost to follow-up. The patients were diagnosed and underwent surgery in the First Affiliated Hospital of Xinjiang Medical University (Urumchi, China) between January 2000 and December 2010. The tumors were pathologically confirmed as clinical stage I-II invasive non-specific breast cancer. The clinical data were complete (Table I). Among the cases, there were 446 Han patients and 263 Uygur patients. The patients were followed-up for 2-10 years and 21 cases were censored. The patients that succumbed to other causes or were lost to follow-up at the time of last contact or prior to the study cut-off were censored. According to breast cancer molecular subtypes, 519 cases were selected, including 188 cases of luminal A $\left(36.2 \%\right.$; $\mathrm{ER}^{+}, \mathrm{PR}^{+}$, Her-2 $\left.2^{-}\right), 128$ cases of luminal B (24.7\%; $\left.\mathrm{ER}^{+}, \mathrm{PR}^{+}, \mathrm{Her}-2^{+}\right)$, 97 cases of Her-2 overexpression (18.7\%; ER $\alpha^{-}, \mathrm{PR}^{-}, \mathrm{Her}-2^{+}$) and 106 cases of basal-like types (20.4\%; ER $\left.\alpha^{-}, \mathrm{PR}^{-}, \mathrm{Her}-2^{-}\right)$.

Prior written and informed consent was obtained from every patient and the study was approved by the Ethics Review Board of Xinjiang Medical University.

Immunohistochemistry. Breast cancer tissue samples were fixed with $10 \%$ formaldehyde for $24 \mathrm{~h}$, embedded in paraffin 
and sliced into $3-\mu \mathrm{m}$ thick sections. Following dewaxing with xylene, the sections were treated with antigen retrieval reagents. After blocking, the sections were incubated with primary antibodies at $37^{\circ} \mathrm{C}$ in the dark for $1 \mathrm{~h}$. The samples were then washed with phosphate-buffered saline (PBS) and secondary antibodies were added and incubated in the dark for $30 \mathrm{~min}$. The sections were developed with 3,3'-diaminobenzidine chromogenic reagent. Finally, the sections were counterstained with hematoxylin and eosin. A positive sample was set up as a positive control and PBS, instead of primary antibody, was used as a negative control. ER $\beta$ antibodies and the working solution were purchased from Fuzhou Maixin Biotechnology Development Co., Ltd. (Fuzhou, China). ER $\alpha$ and Her-2 antibodies were obtained from Gene Tech (Shanghai) Co., Ltd. (Shanghai, China). Primary ER $\beta$ rabbit anti-human polyclonal antibody and HRP-polymer rabbit anti-mouse antibody were purchased from Yueyan Biotech Company (Shanghai, China). Primary $\mathrm{ER} \alpha$ rabbit anti-human monoclonal antibody, primary PR rabbit anti-human monoclonal antibody, primary Her-2 rabbit anti-human monoclonal antibody and HRP-polymer rabbit anti-human antibody were purchased from ZSGB Biotech Company (Beijing, China).

Determination of expression levels. For the determination of $\mathrm{ER} \beta$ expression, cells with brown or yellow staining in the nucleus were considered as ER $\beta$-positive cells. ER $\beta$-positive cells were then counted. The ER $\beta$-positive rate was the ratio of the number of ER $\beta$-positive cells to the total number of cells. An ER $\beta$-positive rate of $<1 \%$ was defined as $\operatorname{ER} \beta(-)$, a positive rate between 1 and $10 \%$ was defined as $\operatorname{ER} \beta(+)$, an ER $\beta$-positive rate between $>10$ and $50 \%$ was defined as $\operatorname{ER} \beta(++)$ and an $\operatorname{ER} \beta$-positive rate of $>50 \%$ was $\operatorname{ER} \beta(+++)$.

For the determination of ER $\alpha$ expression, cells with brown or yellow particles in the nucleus were considered as ER $\alpha$-positive cells. Expression levels of ER $\alpha$ were divided into four levels: $\operatorname{ER} \alpha(-)$, positive rate $<30 \%$; $\operatorname{ER} \alpha(+)$, positive rate between 30 and 40\%; $\mathrm{ER} \alpha(++)$, positive rate between $>40$ and $60 \%$; ER $\alpha(+++)$, positive rate $>60 \%$ (4).

For the determination of Her-2 expression, the Her-2 Detection Guide published by the Chinese Journal of Pathology in 2009 was used (5). Her-2 expression was defined as follows: Her-2 (-), no staining; Her-2 (+), weak or incomplete cell membrane staining; Her-2 (++), $>10 \%$ of invasive cancer cells showing weak to moderate intensity with complete but non-uniform membrane staining or $<30 \%$ of invasive cancer cells showing; Her-2 (++), $>30 \%$ of invasive cancer cells showing strong, complete and uniform membrane staining.

Statistical analysis. Data were analyzed using SPSS 17.0 (SPSS, Inc., Chicago, IL, USA) and differences were compared using a $\chi^{2}$ test. $\mathrm{P}<0.05$ was considered to indicate a statistically significant difference.

\section{Results}

Expression levels of ER $\beta, E R \alpha$ and Her-2 in breast cancer. To determine the expression levels of ER $\beta, \mathrm{ER} \alpha$ and Her-2 in breast cancer tissue, immunohistochemical staining was
Table I. Clinical data of Uygur and Han breast cancer patients.

Clinical features

Cases, n $(\%)$

Ethnicity
Uygur
Han
Age, years
$\leq 49$
$\geq 50$

$263(37.1)$

$446(62.9)$

Tumor size, $\mathrm{cm}$

$\leq 2$

$>2 \leq 5$

377 (53.2)

332 (46.8)

$$
>5
$$

$100(14.1)$

Histological grade

Grade I

125 (17.6)

Grade II

396 (55.9)

Grade III

188 (26.5)

Pathological stage

Stage I

$312(44.0)$

Stage II

$397(56.0)$

Lymph node metastasis

Negative

$412(58.1)$

Positive

297 (41.9)

ER $\beta$ expression

(-)

$380(53.6)$

(+)

$201(28.3)$

(++)

$69(9.7)$

$(+++)$

59 (8.3)

ER $\alpha$ expression

$(-)$

$302(42.6)$

(+/++)

169 (23.8)

$(+++)$

238 (33.6)

Her-2 expression

(-)

$391(55.1)$

(+)

88 (12.4)

$(++)$

55 (7.8)

(+++)

175 (24.7)

Molecular subtype

Luminal A

$188(26.5)$

Luminal B

$128(18.1)$

Her-2 overexpression

$97(13.7)$

Basal-like

$106(15.0)$

ER, estrogen receptor; Her-2, human epidermal growth factor receptor-2.

performed. Representative results are shown in Fig. 1. Cells with blue staining were classified as negative expression cells and cells with brown staining were classified as positive expression cells. ER $\beta$ expression levels were divided into $\operatorname{ER} \beta(-),(+),(++)$ and $(+++)$ (Fig. 1A-D, respectively). ER $\alpha$ expression levels were divided into $\operatorname{ER} \alpha(-),(+/++)$ and $(+++)$ (Fig. 1E-G, respectively). Her-2 expression levels were divided 
Table II. Comparison between ER $\beta$ expression levels in Uygur and Han breast cancer patients.

\begin{tabular}{lccc}
\hline ER $\beta$ expression & Uygur, n $(\%)$ & Han, n (\%) & $\chi^{2}$ value \\
\hline$(-)$ & $125(47.5)$ & $255(57.2)$ & 9.596 \\
$(+)$ & $77(29.3)$ & $124(27.8)$ & \\
$(++)$ & $31(11.8)$ & $38(8.5)$ & \\
$(+++)$ & $30(11.4)$ & $29(6.5)$ & \\
\hline
\end{tabular}

${ }^{\mathrm{a}} \mathrm{P}<0.05$, Pearson's $\chi^{2}$ test. ER, estrogen receptor.

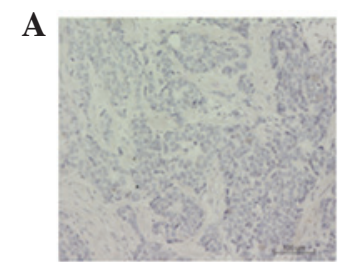

$\mathbf{E}$

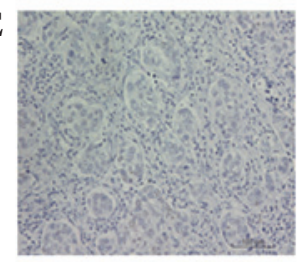

I

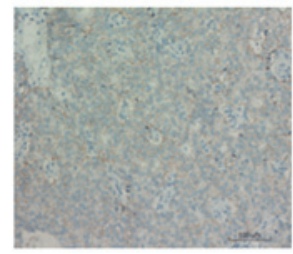

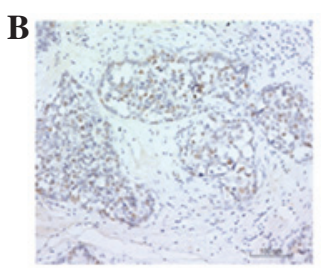

C
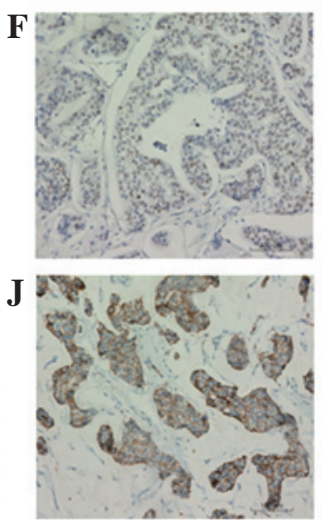
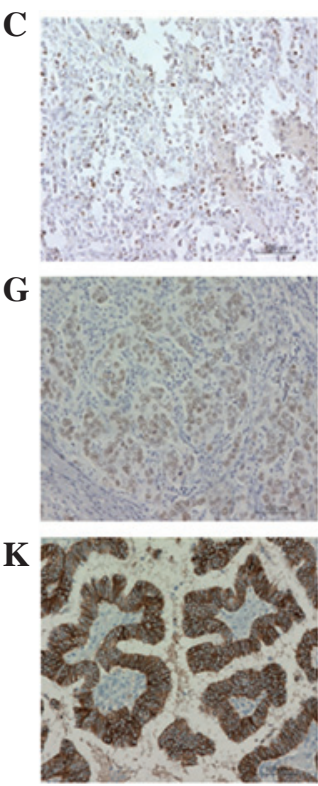

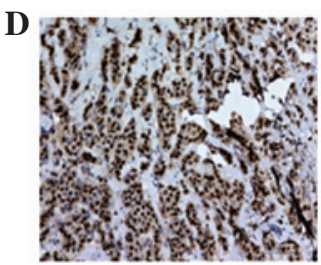

$\mathbf{H}$

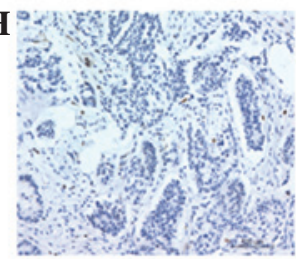

Figure 1. Expression of ER $\beta, E R \alpha$ and Her-2 in breast cancer tissue. Expression of ER $\beta$, ER $\alpha$ and Her-2 was determined by immunohistochemistry. Representative images were shown. Cells with brown staining were positive cells and cells with blue staining were negative cells. Magnification, $\mathrm{x} 400$, (A-D) Stained with ER $\beta$ antibody. (E-G) Stained with ER $\alpha$ antibody. (H-K) Stained with HER2 antibody.

into Her-2 (-), (+), (++) and (+++) (Fig. 1H-K, respectively). Molecular subtypes of breast cancer were defined based on the expression levels of ER $\alpha$ and Her-2.

Positive ER $\beta$ expression is higher in Uygur breast cancer patients. To compare the difference in ER $\beta$ expression levels between Uygur and Han patients, a $\chi^{2}$ test was performed. The results are shown in Table II. The percentage of ER $\beta$ (-) in Uygur patients $(47.5 \%)$ was lower than that in Han patients $(57.2 \%)$. However, percentages of $\operatorname{ER} \beta(+),(++)$ and $(+++)$ in Uygur patients were $29.3,11.8$ and $11.4 \%$, respectively, which were higher than those in Han patients (27.8, 8.5 and 6.5\%, respectively). Statistically, the ER $\beta$-positive expression rate in Uygur patients was significantly higher when compared with Han patients $(\mathrm{P}<0.05)$. This result indicates that Uygur patients exhibited higher levels of ER $\beta$ expression.

Positive ERa expression is lower in Uygur breast cancer patients. Differences in ERa expression levels between Uygur and Han patients were also compared with a $\chi^{2}$ test. As shown in Table III, in Uygur patients, the percentage of ER $\alpha(-)$ expression $(48.7 \%)$ was higher than that in Han patients (39.0\%), whereas percentages of $\mathrm{ER} \alpha(+/++)$ and $(+++)$ expression (22.1 and 29.3\%, respectively) were lower when compared with Han patients (24.9 and $36.15 \%$, respectively). Statistically significant differences were observed in ER $\alpha$ expression levels between Uygur and Han patients $(\mathrm{P}<0.05)$. This result demonstrated that Uygur patients had lower levels of ER $\alpha$ expression.

Positive Her-2 expression is higher in Uygur breast cancer patients. Her-2 expression, an additional immunohistochemical indicator of breast cancer, was further analyzed. The difference in Her-2 expression levels between Uygur and Han individuals was similar to ER $\beta$ expression (Table IV). In Uygur patients, the percentage of Her-2 (-) was $49.8 \%$, which was lower than in Han patients $(58.3 \%)$. The percentages of Her-2 (+), (++) and (+++) in Uygur patients were 11.4, 9.9 and $28.9 \%$, respectively, which were higher than those in Han patients (13.0, 6.5 and 22.2\%, respectively). The differences between Uygur and Han patients were statistically significant $(\mathrm{P}<0.05)$, thus, the results indicated that Uygur patients had higher levels of Her-2 expression.

Differences in molecular subtypes between Uygur and Han patients. As previously described, there are four molecular 
Table III. Comparison between ER $\alpha$ expression levels in Uygur and Han breast cancer patients.

\begin{tabular}{lccc}
\hline ER $\alpha$ expression & Uygur, n (\%) & Han, n (\%) & $\chi^{2}$ value \\
\hline$(-)$ & $128(48.7)$ & $174(39.0)$ & 6.472 \\
$(+++)$ & $58(22.1)$ & $111(24.9)$ & $0.039^{a}$ \\
$(+++)$ & $77(29.3)$ & $161(36.1)$ & \\
\hline
\end{tabular}

${ }^{\mathrm{a}} \mathrm{P}<0.05$, Pearson's $\chi^{2}$ test. ER, estrogen receptor.

Table IV. Comparison between Her-2 expression levels in Uygur and Han breast cancer patients.

\begin{tabular}{lccc}
\hline Her-2 expression & Uygur, n (\%) & Han, n (\%) & $\chi^{2}$ value \\
\hline$(-)$ & $131(49.8)$ & $260(58.3)$ & 7.951 \\
$(+)$ & $30(11.4)$ & $58(13.0)$ & \\
$(++)$ & $26(9.9)$ & $29(6.5)$ & \\
$(+++)$ & $76(28.9)$ & $99(22.2)$ & \\
\hline
\end{tabular}

${ }^{\mathrm{a}} \mathrm{P}<0.05$, Pearson's $\chi^{2}$ test. Her-2, human epidermal growth factor receptor 2 .

Table V. Comparison between molecular subtypes in Uygur and Han breast cancer patients.

\begin{tabular}{lccc}
\hline Molecular subtype & Uygur, n (\%) & Han, n (\%) & $\chi^{2}$ value \\
\hline Luminal A & $61(33.3)$ & $127(37.8)$ & 9.092 \\
Luminal B & $37(20.2)$ & $91(27.1)$ & $0.028^{\text {a }}$ \\
Her-2 overexpression & $46(25.1)$ & $51(15.2)$ & $67(19.9)$ \\
Basal-like & $39(21.3)$ & \\
\hline
\end{tabular}

${ }^{\mathrm{a}} \mathrm{P}<0.05$, Pearson's $\chi^{2}$ test. Her-2, human epidermal growth factor receptor 2 .

subtypes of breast cancer, including luminal A, luminal B, Her-2 overexpression and basal-like types. The distributions of these molecular subtypes in Uygur and Han patients were further investigated. As shown in Table V, when compared with Han patients, Uygur patients had a lower percentage of luminal A (33.3 vs. $37.8 \%)$ and luminal B types $(20.2$ vs. 27.1\%), however, had higher levels of Her-2 overexpression (25.1 vs. $15.2 \%)$ and basal-like types (21.3 vs. $19.9 \%)$. These differences between Uygur and Han patients were statistically significant $(\mathrm{P}<0.05)$. Thus, the distributions of molecular subtypes in Uygur breast cancer patients were different from those in Han breast cancer patients.

\section{Discussion}

In the present study, the differences among ER $\beta, \mathrm{ER} \alpha$ and Her-2 expression levels, as well as breast cancer molecular subtype distribution, in Uygur and Han patients were compared.

ER $\beta$ was first identified in mice and rats in 1996 (6). In 1997, Dotzlaw et al (7) observed the expression levels of ER $\beta$ in human tumor tissues. Since then, the clinical significance of ER $\beta$ expression has gained much attention. Järvinen et al (8) detected 55 cases of ER $\beta$ expression out of 92 cases $(59.8 \%)$ of breast cancer; Mann et al (9) detected 78 cases (66\%) out of 118 cases of breast cancer; Fuqua et al (10) detected 184 cases (76\%) out of 242 cases; Han et al (11) detected 66 cases (42.6\%) out of 155 cases. However, there are few studies investigating the difference in ER $\beta$ expression between Uygur and Han populations. In the present study, ER $\beta$ expression levels were compared in 263 Uygur and 446 Han breast cancer patients. The results demonstrated that the percentages of ER $\beta$ (-) in Uygur and Han patients were 47.5 and $57.2 \%$, respectively, which was statistically significant $(\mathrm{P}<0.05)$. In addition, ER $\beta$-positive expression levels in Uygur patients were significantly higher when compared with Han patients $(\mathrm{P}<0.05)$. It has been reported that in other tumors, including esophageal (12) and cervical cancers (13), incidence and gene expression differ among various ethnic groups. These differences may be associated with genetic background, environmental factors, lifestyle, diet and cultural level. The results of the present study indicated that there was also a difference in ER $\beta$ expression in breast cancer between Uygur and Han patients.

$\mathrm{ER} \alpha$ is an important indicator of breast cancer prognosis and endocrine therapy. Elledge et al (14) studied ER $\alpha$ expression in females of various ethnicities, including AfricanAmerican and Caucasian. The results demonstrated that the 
levels of ER $\alpha$ expression were higher in Caucasian and Asian females, while lower in African females. The levels of ER $\alpha$ expression in Hispanic females were intermediate $(14,15)$. These observations indicate that ER $\alpha$ expression exhibits ethnic differences. In the present study, differences were also identified in ER $\alpha$ expression levels between Uygur and Han patients. The ER $\alpha(+++)$ rate was $29.3 \%$ in Uygur patients, which was significantly lower than that in Han patients (36.1\%). Schwartz et al (16) observed that the ER $\alpha$-positive expression rate of Chinese females with primary breast cancer was lower than that of European and American females, indicating that $\mathrm{ER} \alpha$ expression may also be associated with various regions and ethnic factors. Therefore, these observations further indicate that the estrogen-sensitivity of breast cancer patients in Uygur individuals may be lower than that in Han individuals, which may be one of the reasons for the different therapeutic effects of breast cancer in Uygur and Han individuals.

Her-2, a proto-oncogene, is a common breast cancer gene marker that is involved in the regulation of cell growth, proliferation and differentiation. Overexpression of Her-2 often indicates a high degree of malignancy. Al-Abbadi et al (17) compared Her-2 expression levels in breast cancer between Caucasian-Americans and African-Americans. The authors observed that there was no significant difference between the two ethnicities. By contrast, Yang et al (18) observed that the Her-2 expression rate in breast infiltration ductal carcinoma tissues of Han patients was significantly higher than in Uygur patients, indicating that Her-2 expression exhibited ethnic differences. Thus, whether Her- 2 is differentially expressed in different ethnicities remains controversial. In the present study, Her-2 expression was compared between Uygur and Han individuals and a significant difference was observed. The Her-2 (+++) expression rate $(28.9 \%)$ in Uygur individuals was significantly higher when compared with Han individuals (22.2\%; $\mathrm{P}<0.05)$. However, whether the difference was caused by inherent differences in inter-ethnic genomes or the results of different expression progression requires further investigation (18).

Based on the differences observed in gene expression levels in tumor tissues, Perou et al (19) divided breast cancer into five molecular subtypes in 2000, which included luminal A, luminal B, Her-2 overexpression and basal-like types. Different subtypes had different prognoses. Carey et al (20) examined the immunohistochemistry indicators of Caucasian and African-American females with breast cancer from 24 towns and cities in eastern and central North Carolina. The results demonstrated that there was an ethnic difference in basal-like type distribution in this population. Carey et al (20) compared the molecular subtypes of African-Americans and non-African-Americans. The authors observed that the expression levels of basal-like and luminal A types in the two ethnicities differed. In addition, the study revealed that Her-2 overexpression and basal-like types had a higher histological grade and greater cell proliferation capability as compared with other subtypes of breast cancer, indicating poor prognosis of the Her-2 overexpression and basal-like types. The authors also found that luminal A type cases had a better prognosis than other subtypes. However, the differences in breast cancer subtypes of Uygur and Han individuals in Xinjiang were not reported. In the present study, the distribution of various breast cancer molecular subtypes were compared in Uygur and Han patients. Luminal A type was identified to be the main molecular subtype in Uygur and Han individuals (33.3 and $37.8 \%$, respectively), which was similar to the results of a previous study (16). The percentage of luminal A type in Uygur patients was lower than that in Han patients. However, the percentages of basal-like and Her-2 overexpression types in Uygur individuals were higher than those in Han individuals, and the difference was statistically different $(\mathrm{P}<0.05)$. Thus, the results of the present study indicate that breast cancer in Uygur individuals has a higher degree of malignancy than that in Han individuals.

In conclusion, in Xinjiang, the expression levels of ER $\beta$ and Her-2 and the percentages of basal-like and Her-2 overexpression types in Uygur individuals were higher than those in Han individuals. The expression levels of ER $\alpha$ and the percentages of luminal A and luminal B types in Uygur individuals were lower than those in Han individuals. These observations indicate that breast cancer in Uygur patients may have a higher degree of malignancy and poorer prognosis than that of Han patients. However, the underlying mechanisms of these differences require further study. The results of the present study provide experimental evidence for evaluating prognosis and developing individualized comprehensive treatment for Uygur and Han patients with breast cancer.

\section{Acknowledgements}

The study was supported by a grant from the Natural Science Foundation of Xinjiang Uygur Autonomous Region (no. 2011211A069).

\section{References}

1. Li CI, Malone KE and Daling JR: Differences in breast cancer stage, treatment, and survival by race and ethnicity. Arch Intern Med 163: 49-56, 2003.

2. Gao F, Wang J, Liu X, et al: Racial differences in breast cancer survival in Yunnan. Zhong guo yi xue li lun yu shi jian za zi 1: 778-779, 2003 (In Chinese)

3. Newman B, Moorman PG, Millikan R, et al: The Carolina Breast Cancer Study: intergrating population-based epidemiology and molecular biology. Breast Cancer Res Treat 35: 51-60, 1995.

4. Hammond ME, Hayes DF, Wolff AC, et al: American society of clinical oncology/college of american pathologists guideline recommendations for immunohistochemical testing of estrogen and progesterone receptors in breast cancer. J Oncol Pract 6: 195-197, 2010.

5. Breast cancer compiling group: Guidelines for HER2 detection in breast cancer, the 2009 version. Chinese Journal of Pathology 38: 836-840, 2009 (In Chinese).

6. Kuiper GG, Enmark E, Pelto-Huikko M, et al: Cloning of a novel receptor expressed in rat prostate and ovary. Proc Natl Acad Sci USA 93: 5925-5930, 1996.

7. Dotzlaw H, Leygue E, Watson PH and Murphy LC: Expression of estrogen receptor-beta in human tumors. J Clin Endocrinol Metab 82: 2371-2374, 1997.

8. Järvinen TA, Pelto-Huikko M, Holli K and Isola J: Estrogen receptor beta is coexpressed with ERalpha and PR and associated with nodal status, grade, and proliferation rate in breast cancer. Am J Pathol 156: 29-35, 2000.

9. Mann S, Laucirica R, Carlson N, et al: Estrogen receptor beta expression in invasive breast cancer. Hum Pathol 32: 113-118, 2001.

10. Fuqua SA, Schiff R, Parra I, et al: Estrogen receptor beta protein in human breast cancer: correlation with clinical tumor parameters. Cancer Res 63: 2434-2439, 2003. 
11. Han J, Wang PJ, Tang RY, et al: The expression of estrogen receptor $\alpha, \beta$ in different breast tissues and its relation with breast cancer. Tongji xue bao 26: 21-24, 2005 (In Chinese).

12. Li Y, Wu MB, Zhao XX, et al: Loss of heterozygosity and cloning of human chromosome 3p24 in esophageal carcinoma. Xinjiang Yi Ke Da Xue Xue Bao 26: 224-226, 2003 (In Chinese).

13. Chen R, Li TF, Wang XL, et al: Clinical epidemiological analysis of cervical carcinoma of 2417 cases in Xinjiang. Zhonghua Zhong Liu Fang Zhi Za Zhi 15: 329-331, 2008 (In Chinese).

14. Elledge RM, Clark GM, Chamness GC and Osborne CK: Tumor biologic factors and breast cancer prognosis among white, Hispanic, and black women in the United State. J Natl Cancer Inst 86: 705-712, 1994.

15. Miller BA, Hankey BF and Thomas TL: Impact of sociodemographic factors, hormone receptor status, and tumor grade on ethnic differences in tumor stage and size for breast cancer in US women. Am J Epidemiol 155: 534-545, 2002.

16. Schwartz LH, Koerner FC, Edgerton SM, et al: pS2 expression and response to hormonal therapy in patients with advanced breast cancer. Cancer Res 51: 624-628, 1991.
17. Al-Abbadi MA, Washington TA, Saleh HA, et al: Differential expression of HER-2/NEU receptor of invasive mammary carcinoma between Caucasian and African American patients in the Detroit metropolitan area. Correlation with overall survival and other prognostic factors. Breast Cancer Res Treat 97: 3-8, 2006.

18. Yang H, Shi X, Lv X and Li H: The difference in expressions of CD44v5 and HER4 between Uygur and Han with breast invasive duct carcinoma. Zhongguo Lao Nian Xue Za Zhi 26: 589-590, 2006 (In Chinese).

19. Perou CM, Sørlie T, Eisen MB, et al: Molecular portraits of human breast tumours. Nature 406: 747-752, 2000.

20. Carey LA, Perou CM, Livasy CA, et al: Race, breast cancer subtypes, and survival in the Carolina Breast Cancer Study. JAMA 295: 2492-2502, 2006. 